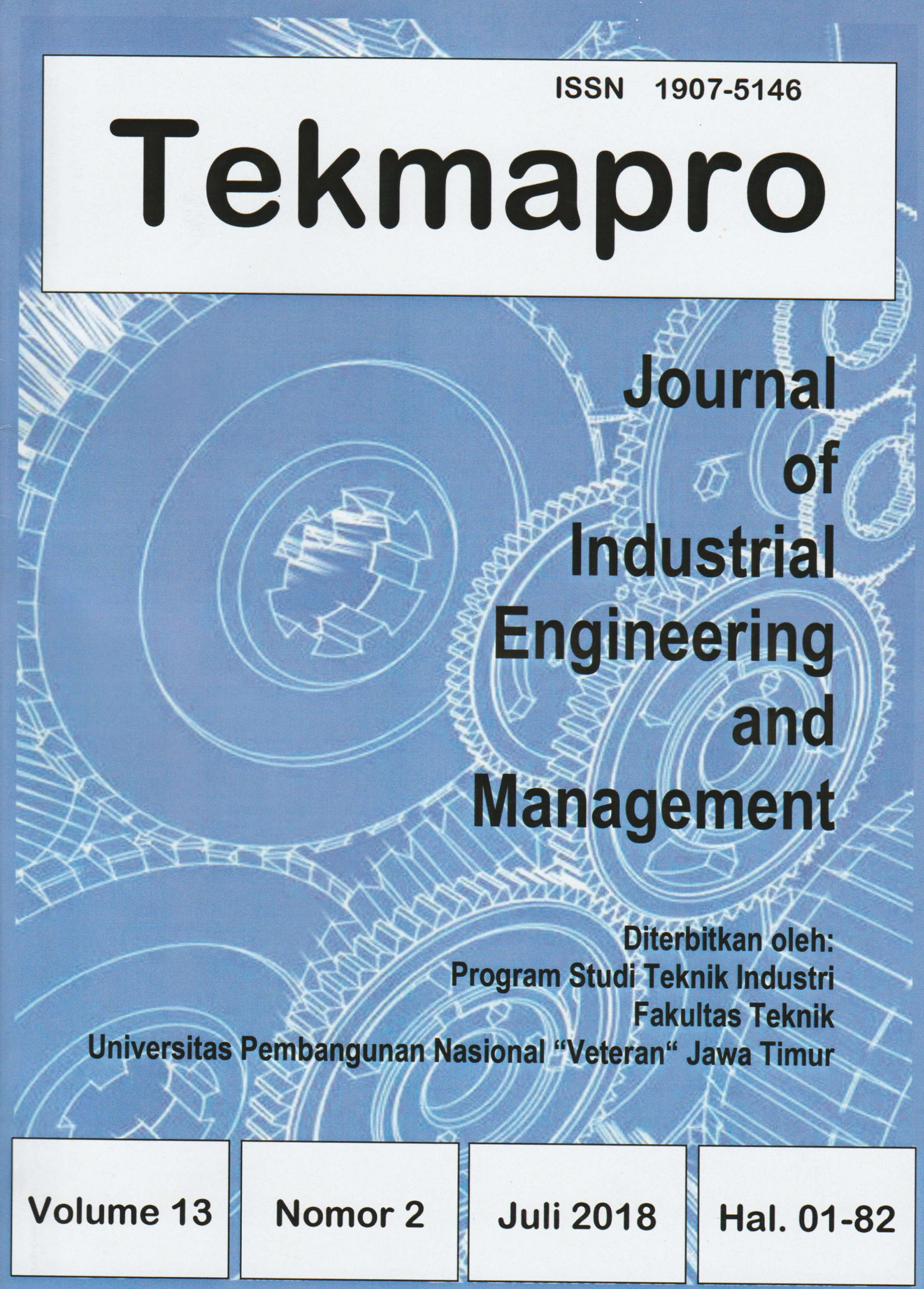




\section{TEKMAPRO}

\section{Pelindung/Patron}

Dekan Fakultas Teknik

Dean of Technic Faculty

Ketua Pengarah/Advisor

Ketua Program Studi Teknik Industri

Chief of Industrial Engineering Department

Mitra Bestari / Reviewers

Udisubakti Ciptomulyono, Prof.,Dr.,Ir.,M.Eng.Sc.

Muslimin, Dr.,Ir., MSIE.

Ketua Editor/Editor in Chief

Farida Pulansari, Dr.,ST.,MT.,IPM.

\section{Penyunting Ahli / Editor}

Minto Waluyo, Dr.,Ir.,MM.

Sunardi T. Koesugito, Dr.,Ir.,MT.

Dira Ernawati, Dr.,ST.,MT.

Dwi Sukma D., ST.,MT.

Handoyo, Ir. MT.

\section{Penyuting Pelaksana / Editoral Board}

Kinanti Resmi Hayati, S.Hum., M.A.

Titi Setiyoningsih, S.Pd., M.Pd.

Kesekretariatan dan Pendistribusian / Secretarity and Distribution Purwati, ST.

Iriani, Ir. MMT.,

Alamat Redaksi:

Jurusan Teknik Industri Fakultas Teknik UPN "Veteran" Jawa Timur

Jalan Raya Rungkut Madya Gunung Anyar, Surabaya 60294

Telp (031) 8782179 Fax. (031) 8782257 Email: tekmapro.ti.upn@gmail.com 


\section{DAFTAR ISI}

Volume 13 Nomor 2

Analisis Teori Permainan Dan Swot Untuk Penentuan Strategi Pemasaran

Handphone (Study Kasus Di Sidoarjo)

Renny Agustini S, Rusindiyanto

Prodi Teknik Industri, FT-UPN "Veteran" Jawa Timur

Analisis Pengendalian Persediaan Just In Time Bahan Baku Pakan

Ternak Untuk Meminimumkan Biaya PersediaanDi Pt. Japfa Comfeed

Eko Nur Cahyono, Erlina Purnamawati

Prodi Teknik Industri, FT-UPN "Veteran" Jawa Timur

Rancang Bangun Sistem Informasi Ekspor Impor Pt. Xyz Menggunakan Bahasa

Pemograman Php Dan Database Mysql

Yuli Fidiana, Ari Basuki, Weny Findiastuti

Fakultas Teknik Prodi Teknik Industri Universitas Trunojoyo Madura

Analisis Ergonomi Pada Proses Pembuatan Tahu Untuk Mengurangi Resiko Cidera Musculoskeletal Disorder (Msds)

Nurfajriah, Rifa Arifati

Prodi Teknik Industri, FT-UPN "Veteran" Jakarta

Analisis Tingkat Beban Kerja Operator Automated Stacking Crane (ASC) Dengan Metode Nasa-Tlx (National Aeronautics And Space Administration Task Load Index) Di Pt. Terminal Teluk Lamong Surabaya

Akmal Suryadi, F.I.Zadi, dan Dwi Sukma D.

Prodi Teknik Industri, FT-UPN "Veteran" Jawa Timur

Analisis Model Hubungan Kepuasan Dan Loyalitas Pelanggan Transportasi Online Mohammad Rachman Waluyo

Prodi Teknik Industri, FT-UPN "Veteran" Jakarta

Perancangan Alat Pemotong Mata Bibit Tebu Dengan Metode Value Engineering Hasbi Assiddiqi, Dira Ernawati, Kinanti Resmi Hayati

Prodi Teknik Industri, FT-UPN "Veteran" Jawa Timur

Penjadwalan Maintenance Mesin DD10 Dengan Menggunakan Metode Markov Chain Alfianita Savitri Sholeh, Ika Deefi Anna, Trisita Novianti, Weny Findiastuti Program Studi Teknik Industri, Jurusan Teknik Industri dan Mesin, Fakultas Teknik, Universitas Trunojoyo Madura

Evaluasi Kinerja Perusahaan Menggunakan Metode Smart System Di Pt Panca Graha Pratama

Raditya Yudha Ekaputra, Endang Pudji. W

Prodi Teknik Industri, FT-UPN "Veteran" Jawa Timur

Kebutuhan Standar Kualitas Pelayanan Pada Unit Usaha Pergudangan Pt Persero Batam Albertus L. Setyabudhi, Aprilia Melisa, Refdilzon Yasra

Program Studi Teknik Industri, STT Ibnusina, Batam 


\title{
KEBUTUHAN STANDAR KUALITAS PELAYANAN PADA UNIT USAHA PERGUDANGAN PT PERSERO BATAM
}

\author{
Albertus L. Setyabudhi, Aprilia Melisa, Refdilzon Yasra \\ JL. Teuku Umar - Pelita - Lubuk Baja, Batam, 085760904014 \\ Program Studi Teknik Industri, STT Ibnusina, Batam \\ abyan@stt-ibnusina.ac.id, apriliamelisa08@gmail.com
}

\begin{abstract}
Abstrak
PT PERSERO BATAM adalah perseroan atau Badan Usaha Milik Negara menurut Peraturan Pemerintah nomor 43 tahun 1973 tentang penyertaan modal negara untuk pendirian perusahaan perseroan, salah satu usahanya adalah Pergudangan Laut Dan Udara, Bongkar Muat, Transportasi /Forwarding, Integrated Logistic. Dalam pelayanannya selama 5 tahun terakhir mengalami penurunan permintaan customer, maka dari itu penelitian ini bertujuan untuk merancang standar kualitas pelayanan untuk meningkatkan permintaan customer pada unit sewa gudang untuk mengetahui indikator indikator yang mempengaruhi penurunan jumlah customer agar dijadikan panduan penyusunan standar kualitas. Peneliti mengambil sampel sebanyak 20 responden dan merancang standar kualitas pelayanan menggunakan metode servqual, hasil dari penelitian ini adalah ada 10 indikator yang dijadikan dasar penyusunan standar kualitas pelayanan dengan mengutamakan dimensi Responsivenes (daya tanggap) karena suara responden menunjukan daya tanggap paling berpengaruh, ditemukannya gap sebesar -0.9. Penulis menyarankan agar perusahaan lebih mengedepankan pelayanan yang maksimal terhadap customer guna meningkatkan permintaan sewa gudang.
\end{abstract}

Kata Kunci : Pelayanan, Sewa Gudang, Servqual

\begin{abstract}
PT PERSERO BATAM is a company or a State-Owned Enterprise according to Government Regulation number 43 of 1973 concerning state capital participation for the establishment of a company company, one of its businesses is Sea and Air Warehousing, Loading and Unloading, Transportation / Forwarding, Integrated Logistics. In its service for the past 5 years, there has been a decrease in customer demand, therefore this study aims to design service quality standards to increase customer demand in warehouse rental units to find out indicators that affect the decrease in the number of customers to be used as guidelines for preparing quality standards. The researcher took a sample of 20 respondents and designed service quality standards using the servqual method, the results of this study were 10 indicators that formed the basis for the preparation of service quality standards by prioritizing the responsiveness because respondents' voices showed the most influential responsiveness, finding a gap of -0.9. The author suggests that companies prioritize maximum service to customers in order to increase the demand for warehouse rental.
\end{abstract}

Keywords: Services, Warehouse Rentals, Servqual 


\section{PENDAHULUAN}

PT PERSERO BATAM adalah perseroan atau Badan Usaha Milik Negara menurut Peraturan Pemerintah nomor 43 tahun 1973 tentang penyertaan modal negara untuk pendirian perusahaan perseroan, dalam unit usaha pergudangannya selama lima tahun terakhir mengalami penurunan jumlah permintaan, mulai dari tahun 2013 dengan index jumlah permintaan 95.20\%, dalam tahun 2017 menjadi 85.20\%. hal ini disebabkan banyaknya jumlah keluhan yang masuk sehingga mengakibatkan penurunan jumlah permintaan customer unit usaha sewa gudang, penelitian ini bertujuan untuk merancang standar kualitas pelayanan agar meningkatkan jumlah permintaan agar mengetahui indikator- indikator yang akan dijadikan standar layanan melalui suara customer tetap, dalam pelayanannya sejak tahun 1973 persero batam hanya memiliki standar operasional namun belum memiliki standar kualitas pelayanan dalam unit usaha pergudangan, sebab dalam pelayanan sangatlah berpengaruh besar dalam income yang didapatkan perusahaan melalui permintaan customer. Batasan masalahnya hanya dalam unit customer service pergudangan dalam lima tahun terakhir.

\section{METODE PENELITIAN}

Penelitian ini bertempat di PERSERO BATAM pada bagian Custumer Service unit Pergudangan yang beralamat di Batu Ampar, Kota Batam, Indonesia, penelitian ini mulai berjalan pada bulan maret dan selesai pada bulan September, adapun jenis data yang diambil dalam penelitian ini adalah data primer yang berupa laporan, data customer, dan index permintaan custumer, dan data primer berupa buku, dan jurnal yang berhubungan dengan penelitian, berikut ini adalah metode pengumpulan data yang dilakukan dalam penelitian :

1) Observasi

2) Wawancara

3) Studi Literatur

4) Kuisioner

Metode Pengolahan data yang digunakan dalam penelitian adalah service quality, metode ini digunakan untuk mengukur sejauh mana kepuasan customer terhadap pelayanan yang diberikan persero batam, adapun taharpan tahapan perancangan yang dilakukan :

1) Menentukan data kepuasan pelanggan dan data tingkat kepentingan atribut dengan menggunakan metode servqual.

2) Penggolongan atribut berdasarkan dimensi servqual.

3) Setelah penggolongan atribut berdasarkan dimensi kemudian pengolahan data untuk menemukan nilai persepsi responden,

4) Pengolahan berikutnya untuk menemukan nilai harapan responden,

5) Menentukan gap dari hasil nilai persepsi dan harapan kemudian merumuskan standar kualitas pelayanan dengan menggunakan tingkat kepentingan. 


\section{HASIL DAN PEMBAHASAN}

\section{Pengumpulan Data}

Pada pengumpulan data yang digunakan dalam penelitian ini, ada 20 customer tetap yang menjadi responden langsung, penetapan ini berdasarkan sample bertujuan untuk mendapatkan hasil yang terbaik.

\section{Data Keinginan Pelanggan}

Kuisioner disusun berdasarkan kelima dimensi servqual yaitu Tangibles (bukti terukur), Reliability (keandalan), Responsiveness (daya tanggap), Assurance (jaminan), dan Empathy (empati), berikut ini adalah jawaban dari responden atas kuisioner yang diberikan :

Tabel 2. Data Hasil Jawaban 20 Responden

\begin{tabular}{|c|c|c|c|c|c|c|c|c|c|c|}
\hline \multirow{2}{*}{ NO } & \multicolumn{7}{|c|}{ JAWABAN DARI PERTANYAAN } \\
\cline { 2 - 11 } & $\mathbf{E 1}$ & $\mathbf{E 2}$ & $\mathbf{E 3}$ & $\mathbf{E 4}$ & $\mathbf{E 5}$ & $\mathbf{E 6}$ & $\mathbf{E 7}$ & $\mathbf{E 8}$ & $\mathbf{E 9}$ & $\mathbf{E 1 0}$ \\
\hline 1 & 4 & 4 & 3 & 4 & 4 & 4 & 4 & 3 & 4 & 4 \\
\hline 2 & 2 & 2 & 2 & 2 & 2 & 3 & 3 & 2 & 2 & 2 \\
\hline 3 & 3 & 3 & 4 & 3 & 3 & 2 & 2 & 3 & 3 & 3 \\
\hline 4 & 2 & 2 & 2 & 2 & 2 & 1 & 3 & 1 & 2 & 2 \\
\hline 5 & 4 & 2 & 3 & 3 & 2 & 3 & 3 & 4 & 3 & 2 \\
\hline 6 & 2 & 2 & 3 & 4 & 2 & 2 & 3 & 3 & 4 & 2 \\
\hline 7 & 2 & 3 & 2 & 2 & 2 & 4 & 2 & 3 & 2 & 2 \\
\hline 8 & 2 & 4 & 3 & 3 & 3 & 4 & 4 & 1 & 3 & 3 \\
\hline 9 & 2 & 2 & 3 & 3 & 3 & 2 & 3 & 2 & 3 & 3 \\
\hline 10 & 2 & 2 & 3 & 2 & 2 & 2 & 2 & 3 & 2 & 2 \\
\hline 11 & 2 & 2 & 3 & 3 & 3 & 3 & 2 & 1 & 3 & 3 \\
\hline 12 & 2 & 2 & 2 & 1 & 2 & 3 & 3 & 3 & 1 & 2 \\
\hline 13 & 3 & 2 & 3 & 2 & 2 & 3 & 3 & 1 & 2 & 2 \\
\hline 14 & 2 & 2 & 2 & 2 & 2 & 2 & 2 & 2 & 2 & 2 \\
\hline 15 & 3 & 2 & 2 & 3 & 2 & 2 & 2 & 2 & 3 & 2 \\
\hline 16 & 4 & 2 & 2 & 3 & 2 & 1 & 2 & 2 & 3 & 2 \\
\hline 17 & 2 & 3 & 3 & 3 & 2 & 2 & 3 & 1 & 3 & 2 \\
\hline 18 & 3 & 3 & 2 & 2 & 3 & 4 & 3 & 3 & 2 & 3 \\
\hline 19 & 4 & 4 & 4 & 4 & 3 & 4 & 4 & 4 & 4 & 3 \\
\hline 20 & 3 & 3 & 2 & 3 & 3 & 3 & 3 & 3 & 3 & 3 \\
\hline
\end{tabular}

\section{Data Responden}

Dari table tersebut dapat disimpulkan persentase berdasarkan jenis kelamin dan berdasarkan umur, persentase didapatkan dari 20 responden yang terdaftar sebagai customer tetap persero batam dalam unit usaha pergudangan perusahaan, berikut ini persentase responden berdasarkan jenis kelamin dan umur : 
a. Berdasarkan Jenis Kelamin

Tabel 3. Persentase jumlah jenis kelamin Responden

\begin{tabular}{|c|c|c|c|}
\hline NO & JENIS KELAMIN & JUMLAH & PERSENTASE (\%) \\
\hline 1 & LAKI- LAKI & 17 & $85 \%$ \\
\hline 2 & PEREMPUAN & 3 & $15 \%$ \\
\hline
\end{tabular}

pengolahan data spss menunjukan bahwa dari 20 responden terdapat 7 orang atau $85 \%$ laki-laki dan sisanya sebesar 3 orang, dengan presentasi berjenis kelamin perempuan sebanyak $15 \%$, peneliti di domisili oleh laki-laki.

b. Berdasarkan Umur

Tabel 4. Persentase jumlah umur Responden

\begin{tabular}{|c|c|c|c|}
\hline NO & UMUR & JUMLAH & PERSENTASE (\%) \\
\hline 1 & $15-24$ TAHUN & 1 & $5 \%$ \\
\hline 2 & $25-35$ TAHUN & 11 & $55 \%$ \\
\hline 3 & $>35$ & 9 & $45 \%$ \\
\hline
\end{tabular}

Dari 20 responden terdapat 1 orang yang berusia antara 15-24 tahun dengan persentase 5\%, untuk kategori 25-35 tahun sebanyak 11 orang dengan persentase 55\% dan sebanyak 9 orang dengan kategori umur diatas 35 tahun dengan persentase sebanyak $45 \%$.

\section{Uji Instrumen Data}

a. Uji Validitas

Uji Validitas ini dilakukan untuk mengetahui apakah pertanyaan yang ada didalam kuisioner memenuhi syarat untuk dijadikan data utama dalam penelitian, pengujian ini dilakukan dengan menggunakan program spss, data untuk teknik pengujiannya menggunakan teknik yang sudah disediakan spss,yang menganalisa item dimana analisis ini menghitung korelasi antar tiaptiap pertanyaan dengan skor total dan setiap hasil dari tiap pertanyaan tersebut disebut dengan $\mathrm{r}$ hitung $>\mathrm{r}$ table pada taraf sinifikan penulis mengambil 5\% dengan tingkat kepercayaan $95 \%$ dengan jumlah pertanyaan sebanyak 10 pertanyaan dan 20 Responden.

Tabel 5. Hasil Responden (Uji Validitas)

\begin{tabular}{|c|c|c|c|}
\hline NO ITEM & $\mathbf{r}_{\text {hitung }}$ & $\mathbf{r}_{\text {tabel }}$ & KETERANGAN \\
\hline P1 & $.623^{* *}$ & 0.4444 & VALID \\
\hline P2 & $.800^{* *}$ & 0.4444 & VALID \\
\hline P3 & $.603^{* *}$ & 0.4444 & VALID \\
\hline P4 & $.745^{* *}$ & 0.4444 & VALID \\
\hline P5 & $.786^{* *}$ & 0.4444 & VALID \\
\hline P6 & $.610^{* *}$ & 0.4444 & VALID \\
\hline P7 & $.640^{* *}$ & 0.4444 & VALID \\
\hline P8 & $.502^{*}$ & 0.4444 & VALID \\
\hline P9 & $.745^{* *}$ & 0.4444 & VALID \\
\hline P10 & $.786^{* *}$ & 0.4444 & VALID \\
\hline
\end{tabular}


a. Uji Reabilitas

Tabel 6. Uji Reabilitas Tingkat Kinerja

Reliability Statistics

\begin{tabular}{|r|r|r|}
\hline \multicolumn{1}{|c|}{ Cronbach's Alpha } & $\begin{array}{l}\text { Cronbach's Alpha Based } \\
\text { on Standardized Items }\end{array}$ & N of Items \\
\hline .860 & .875 & 10 \\
\hline
\end{tabular}

\section{Uji Instrumen Data}

\subsection{Pengkategorian Atribut Layanan Terhadap Dimensi Sevqual}

Dalam pengukuran metode servqual ada lima dimensi yang berpengaruh kedalam penyusunan kuisioner dan sangat penting digolongkan dalam setiap dimensi ini, maka dari itu berikut kelima dimensi yang dirangkum dalam 10 kuisioner yang diberikan kepada responden.

Tabel 7. Hubungan Atribut terhadap kelima Dimensi Servqual

\begin{tabular}{|c|c|l|}
\hline NO & DIMENSI & \multicolumn{1}{c|}{ ATRIBUT LAYANAN } \\
\hline 1 & Tangibles 1 & Perusahaan harus memiliki peralatan dan teknologi terbaru (modern) \\
\hline 2 & Tangibles 2 & $\begin{array}{l}\text { Material dan fasilitas fisik lain yang terkait layanan perusahaan harus tampak } \\
\text { menarik }\end{array}$ \\
\hline 3 & Reliability 1 & $\begin{array}{l}\text { Bila perusahaan berjanji untuk melakukan sesuatu pada waktu yang disepakati, } \\
\text { mereka harus merealisasikannya dengan tepat }\end{array}$ \\
\hline 4 & Reliability 2 & Perusahaan harus memiliki pencatatan yang akurat dan up to date \\
\hline 5 & Responsiveness 1 & $\begin{array}{l}\text { Karyawan perusahaan harus memberitahu pelanggan kapan pastinya layanan akan } \\
\text { disampaikan }\end{array}$ \\
\hline 6 & Responsiveness 2 & Karyawan perusahaan harus selalu bersedia membantu para pelanggan \\
\hline 7 & Assurance 1 & Perilaku karyawan perusahaan harus membuat pelanggan mempercayainya \\
\hline 8 & Assurance 2 & Pelanggan harus dapat merasa aman dalam melakukan transaksi dengan perusahaan \\
\hline 9 & Empaty 1 & $\begin{array}{l}\text { Perusahaan harus memiliki waktu operasi yang sesuai dan nyaman bagi semua } \\
\text { pelanggan }\end{array}$ \\
\hline 10 & Empaty 2 & Perusahaan harus selalu memperhatikan kepentingan pelanggannya \\
\hline
\end{tabular}

\subsection{Perhitungan Rata- Rata Persepsi Kepentingan dan Rata-Rata Harapan Kinerja}

$$
\overline{\mathrm{P}}=\frac{\sum \mathrm{Pi}}{\mathrm{n}} \quad \overline{\mathrm{E}}=\frac{\sum \mathrm{Ei}}{\mathrm{n}}
$$

Tabel 8. Nilai Persepsi Kepentingan dan Harapan Kinerja

\begin{tabular}{|c|c|l|c|c|}
\hline NO & DIMENSI & \multicolumn{1}{|c|}{ ATRIBUT LAYANAN } & $\begin{array}{c}\text { PERSEPSI } \\
\text { KEPENTINGAN }\end{array}$ & $\begin{array}{c}\text { HARAPAN } \\
\text { KINERJA }\end{array}$ \\
\hline 1 & Tang 1 & $\begin{array}{l}\text { Perusahaan harus memiliki peralatan dan teknologi } \\
\text { terbaru (modern) }\end{array}$ & 2.65 & 3.35 \\
\hline 2 & Tang 2 & $\begin{array}{l}\text { Material dan fasilitas fisik lain yang terkait layanan } \\
\text { perusahaan harus tampak menarik }\end{array}$ & 2.55 & 3.4 \\
\hline 3 & Real 1 & $\begin{array}{l}\text { Bila perusahaan berjanji untuk melakukan sesuatu } \\
\text { pada waktu yang disepakati, mereka harus } \\
\text { merealisasikannya dengan tepat }\end{array}$ & 2.65 & 3.3 \\
\hline
\end{tabular}




\begin{tabular}{|c|c|l|c|c|}
\hline 4 & Real 2 & $\begin{array}{l}\text { Perusahaan harus memiliki pencatatan yang akurat } \\
\text { dan up to date }\end{array}$ & 2.7 & 3.4 \\
\hline 5 & Res 1 & $\begin{array}{l}\text { Karyawan perusahaan harus memberitahu } \\
\text { pelanggan kapan pastinya layanan akan } \\
\text { disampaikan }\end{array}$ & 2.45 & 3.35 \\
\hline 6 & Res 2 & $\begin{array}{l}\text { Karyawan perusahaan harus selalu bersedia } \\
\text { membantu para pelanggan }\end{array}$ & 2.8 & 3.25 \\
\hline 7 & Ass 1 & $\begin{array}{l}\text { Perilaku karyawan perusahaan harus membuat } \\
\text { pelanggan mempercayainya }\end{array}$ & 2.35 & 3.55 \\
\hline 8 & Ass 2 & $\begin{array}{l}\text { Pelanggan harus dapat merasa aman dalam } \\
\text { melakukan transaksi dengan perusahaan }\end{array}$ & 2.7 & 3.5 \\
\hline 10 & Emp 2 & $\begin{array}{l}\text { Perusahaan harus memiliki waktu operasi yang } \\
\text { sesuai dan nyaman bagi semua pelanggan } \\
\text { kepentingan pelanggannya }\end{array}$ & 2.45 & 3.35 \\
\hline
\end{tabular}

Berikut ini adalah Grafik dari setiap atribut terhadap persepsi dan harapan :

Grafik 4.1 Perbedaan Nilai antara Persepsi dan Harapan

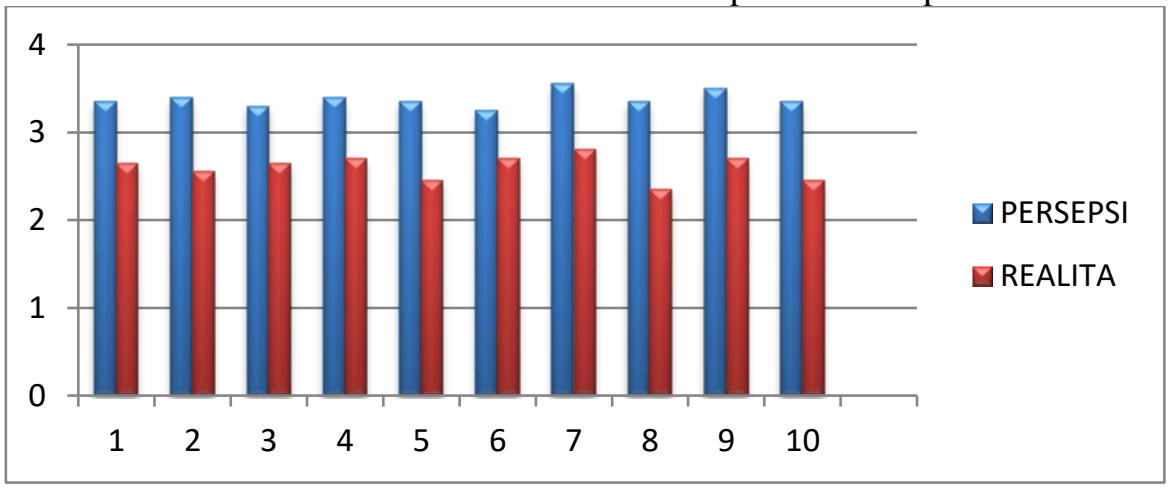

Grafik diatas menunjukan adanya kesenjangan (gap) yang didapat dari masing masing atribut yang selanjutnya akan dihitung mengenai nilai gapnya.

\subsection{Perhitungan Gap pada setiap Atribut}

$$
\mathrm{S}=\overline{\mathrm{P}}-\overline{\mathrm{E}}
$$

Tabel 9. Rata- rata Persepsi dan Harapan Responden

\begin{tabular}{|c|c|l|c|c|c|}
\hline NO & DIMENSI & \multicolumn{1}{|c|}{ ATRIBUT LAYANAN } & $\begin{array}{c}\text { PERSEPSI } \\
\text { KEPENTINGAN }\end{array}$ & $\begin{array}{c}\text { HARAPAN } \\
\text { KINERJA }\end{array}$ & GAP \\
\hline 1 & Tang 1 & $\begin{array}{l}\text { Perusahaan harus memiliki peralatan } \\
\text { dan teknologi terbaru (modern) }\end{array}$ & 2.65 & 3.35 & -0.7 \\
\hline 2 & Tang 2 & $\begin{array}{l}\text { Material dan fasilitas fisik lain yang } \\
\text { terkait layanan perusahaan harus } \\
\text { tampak menarik }\end{array}$ & 2.55 & 3.4 & -0.85 \\
\hline 3 & Real 1 & $\begin{array}{l}\text { Bila perusahaan berjanji untuk } \\
\text { melakukan sesuatu pada waktu yang } \\
\text { disepakati, mereka harus } \\
\text { merealisasikannya dengan tepat }\end{array}$ & $\begin{array}{l}\text { Perusahaan harus memiliki pencatatan } \\
\text { yang akurat dan up to date }\end{array}$ & 2.65 & 3.3 \\
\hline
\end{tabular}




\begin{tabular}{|c|c|c|c|c|c|}
\hline 5 & Res 1 & $\begin{array}{l}\text { Karyawan perusahaan harus } \\
\text { memberitahu pelanggan kapan pastinya } \\
\text { layanan akan disampaikan }\end{array}$ & 2.45 & 3.35 & -0.9 \\
\hline 6 & Res 2 & $\begin{array}{l}\text { Karyawan perusahaan harus selalu } \\
\text { bersedia membantu para pelanggan }\end{array}$ & 2.7 & 3.25 & -0.55 \\
\hline 7 & Ass 1 & $\begin{array}{l}\text { Perilaku karyawan perusahaan harus } \\
\text { membuat pelanggan mempercayainya }\end{array}$ & 2.8 & 3.55 & -0.75 \\
\hline 8 & Ass 2 & $\begin{array}{l}\text { Pelanggan harus dapat merasa aman } \\
\text { dalam melakukan transaksi dengan } \\
\text { perusahaan }\end{array}$ & 2.35 & 3.35 & -1 \\
\hline 9 & Emp 1 & $\begin{array}{l}\text { Perusahaan harus memiliki waktu } \\
\text { operasi yang sesuai dan nyaman bagi } \\
\text { semua pelanggan }\end{array}$ & 2.7 & 3.5 & -0.8 \\
\hline 10 & Emp 2 & $\begin{array}{l}\text { Perusahaan harus selalu memperhatikan } \\
\text { kepentingan pelanggannya }\end{array}$ & 2.45 & 3.35 & -0.9 \\
\hline
\end{tabular}

Perhitungan gap skor dilakukan dengan metode servqual. Gap skor merupakan selisih antara penilaian kualitas pelayanan yang dirasakan (kinerja) dengan kualitas pelayanan yang diharapkan, dengan demikian skor yang bernilai negative (-) adalah atribut yang 'weak' yang perlu diperbaiki, seperti yang diketahui pada tabel keterangan kualitas pelayanan yang didapat. Berikut ini adalah table keterangan lemah atau week yang dihitung berdasarkan tingkat kelemahan setiap respon oleh 20 responden, dalam pernyataan apabila negative maka kualitas palayanan bernilai sangat lemah dan perlu mendapatkan perbaikan.

\subsection{Atribut Layanan berdasarkan Tingkat Kepentingan}

Berikut ini adalah bentuk atribut berdasarkan tingkat kepentingan yang berdasarkan pada gap yang diperolah dari persepsi dan harapan kinerja

Tabel 10. Gap Servqual

\begin{tabular}{|c|c|c|c|c|c|}
\hline NO & DIMENSI & ATRIBUT LAYANAN & $\begin{array}{c}\text { PERSEPSI } \\
\text { KEPENTINGAN }\end{array}$ & $\begin{array}{l}\text { HARAPAN } \\
\text { KINERJA }\end{array}$ & GAP \\
\hline 5 & $\operatorname{Res} 1$ & $\begin{array}{l}\text { Karyawan perusahaan harus } \\
\text { memberitahu pelanggan kapan pastinya } \\
\text { layanan akan disampaikan }\end{array}$ & 2.45 & 3.35 & -0.9 \\
\hline 10 & Emp 2 & $\begin{array}{l}\text { Perusahaan harus selalu memperhatikan } \\
\text { kepentingan pelanggannya }\end{array}$ & 2.45 & 3.35 & -0.9 \\
\hline 2 & Tang 2 & $\begin{array}{l}\text { Material dan fasilitas fisik lain yang } \\
\text { terkait layanan perusahaan harus tampak } \\
\text { menarik }\end{array}$ & 2.55 & 3.4 & -0.85 \\
\hline 9 & Emp 1 & $\begin{array}{l}\text { Perusahaan harus memiliki waktu } \\
\text { operasi yang sesuai dan nyaman bagi } \\
\text { semua pelanggan }\end{array}$ & 2.7 & 3.5 & -0.8 \\
\hline 7 & Ass 1 & $\begin{array}{l}\text { Perilaku karyawan perusahaan harus } \\
\text { membuat pelanggan mempercayainya }\end{array}$ & 2.8 & 3.55 & -0.75 \\
\hline 1 & Tang 1 & $\begin{array}{l}\text { Perusahaan harus memiliki peralatan } \\
\text { dan teknologi terbaru (modern) }\end{array}$ & 2.65 & 3.35 & -0.7 \\
\hline 4 & Real 2 & $\begin{array}{l}\text { Perusahaan harus memiliki pencatatan } \\
\text { yang akurat dan up to date }\end{array}$ & 2.7 & 3.4 & -0.7 \\
\hline 3 & Real 1 & $\begin{array}{l}\text { Bila perusahaan berjanji untuk } \\
\text { melakukan sesuatu pada waktu yang } \\
\text { disepakati, mereka harus } \\
\text { merealisasikannya dengan tepat }\end{array}$ & 2.65 & 3.3 & -0.65 \\
\hline 6 & Res 2 & $\begin{array}{l}\text { Karyawan perusahaan harus selalu } \\
\text { bersedia membantu para pelanggan }\end{array}$ & 2.7 & 3.25 & -0.55 \\
\hline
\end{tabular}




\begin{tabular}{|c|c|l|l|l|l|}
8 & Ass 2 & $\begin{array}{l}\text { Pelanggan harus dapat merasa aman } \\
\text { dalam melakukan transaksi dengan } \\
\text { perusahaan }\end{array}$ & 2.35 & 3.35 & -1 \\
\hline
\end{tabular}

Dan selanjutnya akan dijadikan rancangan standar kualitas pelayanan berdasarkan harapan kinerja dan gap yang didapat.

\section{KESIMPULAN}

Berdasarkan perancangan standar kualitas pelayanan menggunakan metode servqual dengan menemukan nilai gap dan mengkategorikan atribut dengan kelima dimensi servqual yang peneliti gunakan didapatkan usulan rancangan standar kualitas pelayanan sebanyak 10 Atribut sebagai indikator. Berikutnya pengamatan yang peneliti lakukan didapatkan jumlah gap paling besar dengan nilai - 0,9 dalam dimensi Responsivenes (daya tanggap), dengan lebih memprioritaskan responsiveness (daya tanggap) dalam usulan rancangan standar kualitas pelayanan sesuai dengan keinginan customer, maka akan mengurangi jumlah keluhan dan meningkatkan permintaan customer pada unit usaha pergudangan perusahaan.

\section{SARAN}

Adapun saran yang dapat diberikan dalam penelitian agar penelitian ini lebih baik lagi adalah sebagai dari penelitian ini didapat koefisien korelasi antara kualitas pelayanan, tingkat kepuasan pelanggan mempunyai kekuatan hubungan yang lemah-cukup kuat terhadap citra perusahaan, menandakan kedua variable tersebut tidak terlalu kuat membentuk citra perusahaan, Maka, perlu adanya penelitan faktor-faktor lain untuk mengetahui faktor lain yang mempunyai pengaruh kuat pada citra perusahaan.

\section{DAFTAR PUSTAKA}

Parasuraman, A. Zeithhaml, V.A, dan Barry, LL (1990) Delivering Quality Service : Balncing Customer Perceptions Quality and Expectation. The Free Press, New York.

Sulistiyowati1, Wiwik; Hari Supriyanto,Mokh.Suef. Integrasi Metode Servqual, Lean Dan Six Sigma Implementasi : PT.PLN (Persero) Distribusi Jawa Timur, APJ Surabaya Selatan-UPJ Ngagel

Tan, Kay, C, and A. P, Theresia, 2001, Integrating Servqual and Kano's Model into QFD for Service Excellence Development, Managing Service Quality, Volume 11, Number 6

Wijaya, Tony, 2011. "Manajemen Kualitas Jasa”, Penerbit Indeks, Jakarta.

Widarman, Agung, 2011. "Usulan Rancangan Peningkatan Kualitas Pelayanan Dalam Penyelenggaraan Pendidikan dengan Pendekatan Model Integrasi Servqual, Kano, dan $Q F D$, Bandung. 